\title{
Integration of Students' Out-of-Class Work in Teaching-Learning Process
}

\author{
A. Palomares Chust ${ }^{l}$, E. Antonino Daviu ${ }^{l}$, D. de Andrés Martínez ${ }^{l}$, C. Gisbert Domenech ${ }^{l}$, \\ A. Peña Cerdán ${ }^{l}$, J. C. Ruiz Garcia ${ }^{l}, J$. V Ballester Server ${ }^{2}$, C. Villavieja Llorente ${ }^{l}$ \\ Universitat Politècnica de Valèncial ${ }^{1}$, Universitat de València ${ }^{2}$
}

\begin{abstract}
Out-of-Class Work (OCW) is a crucial part of students' learning process. The continuous assessment of students' OCW provides many opportunities to fix students' mistakes and misunderstandings, while improving courses' contents. Among many others, important aspects concerning $O C W$ that are mostly ignored today in the evaluation process relate to: 1) how students hand over assignments and 2) the time they devote to each assignment. The Tools and Strategies for Competences Assessment (TASCA) is an Innovation and Quality Education Team of the Universitat Politècnica de València (UPV). Its goal is to gather and analyze OCW information in order to obtain evidences of the degree of achievement of certain learning outcomes, improve students' on-site learning experience and enrich the course evaluation process. Preliminary results show that the lack of adequate $O C W$ supervision leads to situations where teachers underestimate (or overestimate) the complexity of assignments. This leads to a waste of time or overloads the student. Coordination among courses is of prime importance to adequate students, work to avoid workload peaks. Moreover, there lack of relationship between the time devoted to tasks and the attained results lead to especial cases where despite the time invested in tasks resulting grades are low in general. This may reflect the fact that such tasks are poorly specified or are not adequately connected to courses' contents. Finally, assessing the usefulness of tasks as perceived by students seems also mandatory attending to the impact that such perception has on students' motivation.
\end{abstract}

\section{Introduction}

OCW has acquired a greater relevance in the teaching-learning process after the Bologna process has acted as director plan for university studies. Accordingly, OCW has consolidated as a fundamental strategy to train and develop students' specific competencies and carry out formative and continuous evaluation [1].

Under the general term of "student's OCW" there are hidden many techniques, for promoting and controlling different student's activities, which are rarely addressed in publications and barely used in practice. As such, this $\mathrm{OCW}$ is usually limited to deliver some reports for their subsequent evaluation.
However, the rest of intangible parameters that cannot be captured within a deliverable are lost and are neither controlled nor evaluated. Being able to trace, among other aspects, how students organize and coordinate their work, or the different strategies they deploy, or the time they employ, for reaching their objectives, could be also very useful to enrich the evaluation process and improve the feedback finally provided to students [2].

Knowing the impact that such lack of information may have on students' performance, it is surprising that there are so many difficulties in evaluating the actual OCW carried out by each student. This not only a matter of tracing the time devoted to the various tasks proposed to students, but also a matter of obtaining enough concrete evidences backing up this work. Figure 1 depicts some of aspects requiring further efforts to improve the monitoring the students' OCW in order to guarantee a fair evaluation of such work and the provision of a proper feedback to the student.

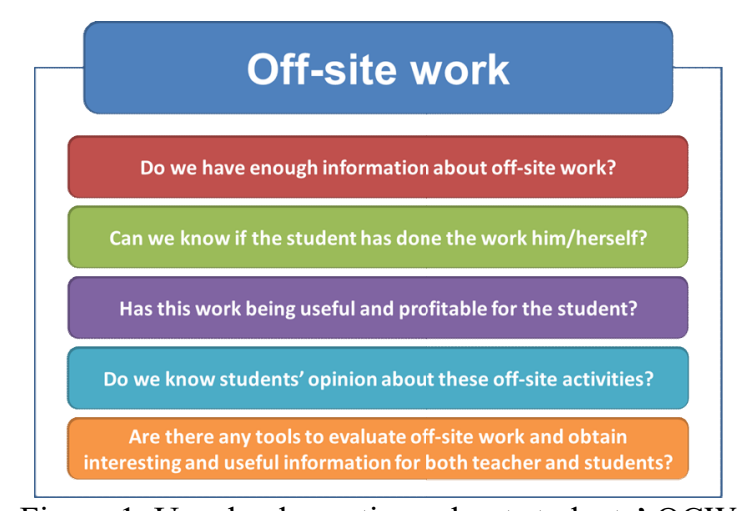

Figure 1. Unsolved questions about students' OCW

\section{Goals}

The "Tools and Strategies for Competences Assessment" (TASCA) "Innovation and Quality Education Team" (EICE) from the Universitat Politècnica de València (UPV), through the "Supporting Formative Assessment Through the Strategies for Gathering OCW Information and Evidences" (A08/13) "Project of Education Innovation and Improvement" (PIME), aims at analysing, applying, and assessing formative and continuous methodologies and strategies to evaluate, in all its dimensions, students' OCW. The goal is to be able to process all the gathered information to improve and adapt the content of in-class course 
materials, and increase students' motivation and participation in lectures, while providing a more specific and adapted feedback to each student. This will increase the level of flexibility provided to students in their learning process by allowing them to suit such process to their particular weaknesses and strengths [3]. Attending to such general goal, the following challenges are formulated:

- Integrate OCW into the general dynamics of the course.

- Determine which activities are most suitable for the different learning outcomes.

- Assess the degree of achievement of students for these learning outcomes.

- Know students' motivation and satisfaction with OCW.

- Adjust the rhythm of in-site classes and activities according to the feedback provided by students [4].

To achieve these goals, TASCA aims at using already existing tools to get information and evidences about students' OCW, evaluate it in a coherent and suitable way [5], and guide students into achieving the courses' learning outcomes. The selected set of tools should assist teachers in:

- Getting concrete proofs of OCW, including those not reflected in a deliverable.

- Estimating the time students devoted to the task.

- Analysing students' workload.

- Getting students' opinion about the activity, degree of satisfaction and usefulness.

- Obtaining information about the work process, not just about the obtained result.

This will unify and give coherence to the whole learning-teaching process, removing the great barrier existing between the evaluation, monitoring, and feedback of in- and OCW [6].

The benefits that this approach may provide to both students and teachers include, but are not limited to:

- Increasing feedback to students about their work, including organisation and process, not just the final result.

- Increasing feedback to teachers through students' opinions and suggestions, which could help to adapt and improve the courses and both the in- and OCW.

- Promoting reflexive activities to improve the students' analysis and criticism capacities.

- Generating more active, dynamic, and participative OCW. This may continue in a fluid and natural way in the classroom.

- Increasing students' motivation.

\section{Planning}

\subsection{State of the art}

The search for information, documentation, and references has been focused on two main areas considered of prime importance for the project:

- References about OCW and tools and processes for its monitoring and quantification

- Search, analysis, and selection of tools enabling the recollection of information about $\mathrm{OCW}$.

At a first moment, we thought of using tools like those employed by companies for tasks management. These project management tools enable managers to add new projects, add people to projects, impute a number of hours to people, etc. Although most of these tools are available for a fee, there are also some open-source free ones, like TRAC [7] or REDMINE [8]. However, these tools are usually very complex and may hinder the recollection of information, so we selected simpler tools, such as questionnaires and spreadsheets as we describe in the project stage 2 , hereafter.

\subsection{Tools definition}

Different tools have been designed to collect and analyse information about OCW. These tools have been adapted according to teachers' criteria, course and work to be performed by students.

- Questionnaires comprising questions, opinions, and comments about the task performed. They include questions about the time and effort devoted to the activity, its suitability and usefulness. These questionnaires were handed as part of the deliverable, and they were proposed for both short (one week) and long (4-5 weeks) duration activities.

- Spreadsheets to estimate students' OCW dedication to different courses along their whole duration (12-14 weeks). This spreadsheet was available as a "Task" in UPV's online learning environment (PoliformaT [9], a customised instance of SAKAI). Students had to fill out this spreadsheet reporting the time devoted to study, completing tasks, and other activities, for each of the selected courses.

\subsection{Use of questionnaires and spreadsheet}

The defined mechanisms for collecting information about students' OCW activity have been applied in the second half of the academic year. Due to the multidisciplinary nature of the team of teachers conforming TASCA, the questionnaires have been adapted for each particular case, taking into account aspects like degree, students' profile, characteristics of the course, and the kind and 
duration of the work to be done. These mechanisms have been applied to different Bachelor's Degree and Master courses, with different duration, and even transversal courses (courses mixing students from different years).

\subsection{Analysis of results}

Information collected during stage 3 has been analyzed, taking into account the different kind of proposed activities. This study has detected a number of common mistakes, so questionnaires and spreadsheet have been adapted and improved accordingly to try to achieve the proposed goals.

\section{Targets and Tools}

The different courses have acted as targets for this first attempt to assess and extract useful information from students' OCW are depicted in Figure 2.

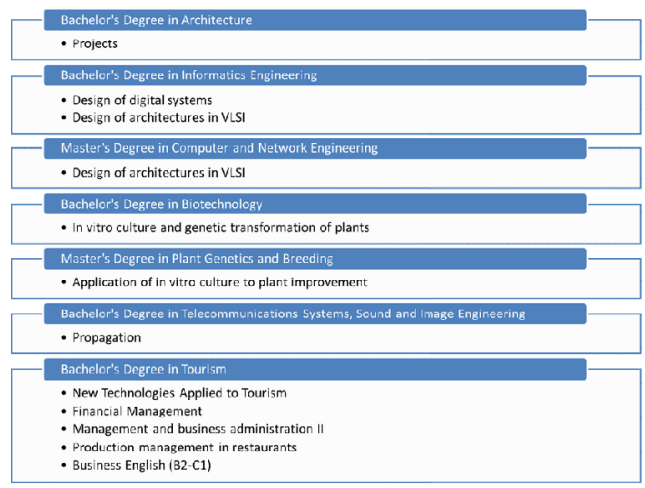

Figure 2. List of target courses

As previously stated, two different kind of tools have been used to obtain the desired information about students' OCW: questionnaires and spreadsheets.

\subsection{Questionnaires}

This type of mechanism consists in a series of open questions to gather information and get immediate feedback about an OCW activity, usually of short duration. The questionnaire was part of the deliverable of the associated activity, so information could be quickly gathered in a fluid manner. Students' answers are more reliable when they fill out the questionnaire just after finishing the activity, as their work is done very recently and they have a very clear opinion about it. So these data are very useful to get immediate feedback about OCW. Table 1 lists the different kind of OCW activities considered and the questions students should answer.

The "Propagation" course is a particular case as, in a first attempt to gather information about their OCW, very few students delivered the questionnaires. So, a second attempt was made but, in this case, delivering the questionnaire was rewarded with a small bonus in the mark of the associated exercise.

This clearly motivated students as about $70 \%$ of them handed out the exercise and questionnaire

Table 1. Analysed OCW activities through the associated questionnaires

\begin{tabular}{|c|c|}
\hline Activity & Questionnaire \\
\hline $\begin{array}{c}\text { A. Reading a } \\
\text { scientific paper } \\
\text { before the lecture, } \\
\text { and answering a } \\
\text { number of relevant } \\
\text { questions. }\end{array}$ & $\begin{array}{l}\text { What is the most interesting } \\
\text { idea you have learned? } \\
\text { Why? } \\
\text { Which question would you } \\
\text { like to get answered in the } \\
\text { next lecture? Why? } \\
\text { What aspects do not require } \\
\text { further explanation after } \\
\text { reading the paper? } \\
\text { How long did it take you to } \\
\text { read the paper and answer } \\
\text { these questions? }\end{array}$ \\
\hline $\begin{array}{l}\text { B. Applying the } \\
\text { contents of a lecture } \\
\text { to students' } \\
\text { projects. }\end{array}$ & $\begin{array}{l}\text { Is the main concept of the } \\
\text { lecture clear? Do you have } \\
\text { any doubts? } \\
\text { Have you found it difficult } \\
\text { to apply it to your project? } \\
\text { Why? } \\
\text { Has this exercise helped you } \\
\text { in clarifying the main } \\
\text { lecture's concepts? } \\
\text { Which new questions or } \\
\text { doubts do you have after } \\
\text { making this exercise? } \\
\text { How long did it take you to } \\
\text { review the lecture and make } \\
\text { the exercise? }\end{array}$ \\
\hline $\begin{array}{l}\text { C. Searching a } \\
\text { paper, extracting } \\
\text { information as } \\
\text { shown in lectures, } \\
\text { and preparing a } \\
\text { presentation about } \\
\text { the paper's } \\
\text { contents. }\end{array}$ & $\begin{array}{c}\text { How long did it take you to } \\
\text { select the paper? } \\
\text { Was it difficult to } \\
\text { comprehend and extract the } \\
\text { information? Why? } \\
\text { What is the conclusion of } \\
\text { the paper? } \\
\text { Have you acquired new } \\
\text { competencies and/or } \\
\text { knowledge? } \\
\text { How long did it take you to } \\
\text { work on the paper and } \\
\text { presentation? }\end{array}$ \\
\hline $\begin{array}{l}\text { D. Solving long } \\
\text { problems about the } \\
\text { content of some } \\
\text { lectures. }\end{array}$ & $\begin{array}{l}\text { How long did it take you to } \\
\text { solve the problem? } \\
\text { Did it allow you to review } \\
\text { and better understand the } \\
\text { lectures' contents? } \\
\text { Do you have questions or } \\
\text { doubts about the content of } \\
\text { the exercise? }\end{array}$ \\
\hline
\end{tabular}




\subsection{Spreadsheet}

This approach has been applied to the courses belonging to the second term of the third year of the Bachelor's Degree in Tourism. Students were asked to register all the OCW devoted to the different courses they were enrolled during this semester.

Unlike questionnaires, this approach only takes into account the time devoted to different activities considered relevant, including "studying", "working on deliverables", and "other activities". To get reliable information about students' OCW activities, they were asked to fill in the information on a weekly basis. Longer time will result in less reliable data and shorter periods will burden students with unnecessary workload. The design of the spreadsheet is depicted in Figure 3.

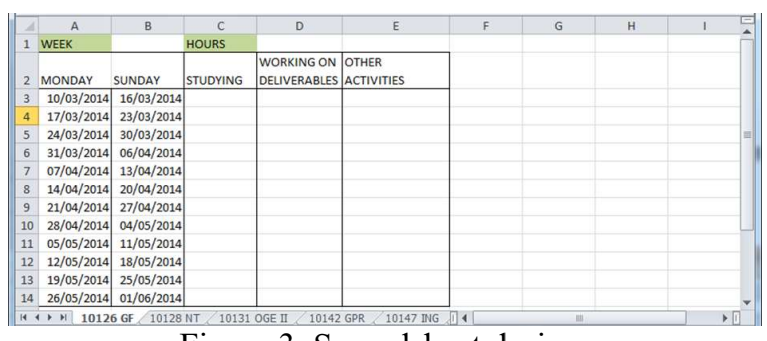

Figure 3. Spreadsheet design

This spreadsheet collects information from 12 weeks, beginning on the week starting on Monday 10th March 2014 until the week starting on Monday 26th May 2014. The information for the first three weeks of the courses is missing, but the OCW in these weeks is usually negligible. Likewise, we lack information about the final period of the term, between the end of the lectures and exams, in which student's OCW is surely very important.

As this activity was not related to any content of the different courses, it was published as a voluntary task in UPV's learning platform. Hence participating students were rewarded with a $10 \%$ of the final mark to motivate their participation. Among the participant, there were roughly 20 students that took all these courses, and between 10 and 20 more that took just some of them.

\section{Results}

Despite the heterogeneity of target courses, OCW activities, and their duration, all the gathered information provides quite useful insights about how to improve these activities and, in general, the courses. These results can be better analysed from the perspective of the kind of mechanisms used to collect the information, and thus the very nature of the collected information.

\subsection{Questionnaires}

It must be noted that questionnaires provide very useful information not only about the time students devoted to the activities, but also about the suitability and usefulness of the activity from students' perspective. These data have enabled us to modify the proposed activities in order to make them clearer, more challenging, and more appealing to students. Due to the heterogeneity of target courses is not feasible to go through all the subtleties of modifying each of the proposed activities, but the collected data have surely contributed to improving all of them.

Nevertheless, information related to the time students' devoted to OCW has been processed exactly in the very same way. On the one hand, the marks obtained for each student in the proposed OCW activity has been plotted with respect to the time it took the student to complete the task. This will help us to determine whether there is any relationship between the time devoted to the task and the marks obtained. As an example, Figure 4 depicts the results obtained for the activity related to searching for a scientific paper, analysing it, and preparing an oral presentation. The very same activity was proposed in two different courses, from the "Bachelor's Degree in Biotechnology" and the "Master's Degree in Plant Genetics and Breeding". This particular activity has been selected because it exemplifies the different cases that have appeared when analysing the whole set of proposed activities.

The first thing to be noted is that it does not seem to be any clear relationship between the assigned marks and the time devoted to the task. There exist high marks for deliverables declaring relatively little time, and low marks for deliverables that reported a long time to complete.

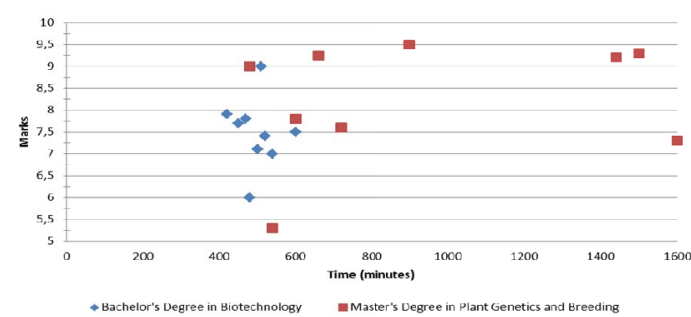

Figure 4. Relationship between marks assigned and time devoted to the task

However, with this kind of graph it is easier to detect possible problems. For instance, the case of the student reporting the longest time devoted to the task. It must be noted that this task was supposed to be finished in about 10 to 12 hours and the student required more than twice this time to finish it. For such an effort, the student did not get as a good mark as it could have been desirable. This could probably point out to some difficulties with the content of related lectures, for instance, and a meeting with the 
student for clarification and guidance may be in order.

On the other hand, it is easy to see that the time devoted by students from these two courses fall into very different ranges. That is why, the cumulative distributed function (CDF) of students having finished the activity in a given time has also been plotted for all the target courses. Figure 5 depicts this function for the activity proposed in the "Bachelor's Degree in Biotechnology" (up) and the "Master's Degree in Plant Genetics and Breeding" (down).
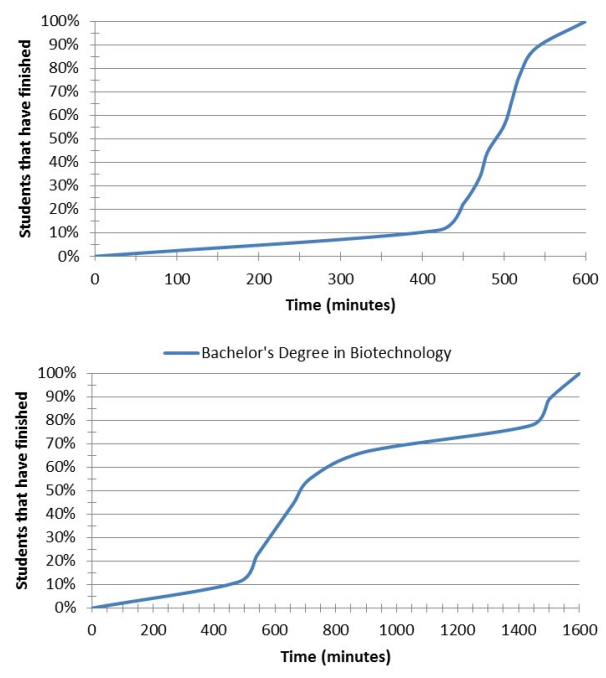

- Master's Degree in Plant Genetics and Breeding

Figure 5. Cumulative distributed function of students having finished the activity in a given time

As can be seen, all the students from the "Bachelor's Degree in Biotechnology" finished the activity before the estimated time (600 to 720 minutes). Nevertheless, it seems that the task is not too easy either, as barely any student completed the deliverable in less than 450 minutes.

In the case of master students just about $40 \%$ of them finished the task in that time. In fact, twice that time was required for $80 \%$ of students to finish the activity. This clearly points out a problem that could be related to the heterogeneity of students enrolled in the master course, whereas degree students have a more homogenous profile that better fits the task at hand. Probably, it could be a good idea to complement the task for master students with a previous lecture or activity for them to acquire a homogeneous knowledge.

\subsection{Spreadsheet}

Through the use of the proposed spreadsheet we gathered information about students' $\mathrm{OCW}$ in five different third year courses, running in parallel, of the "Bachelor's Degree in Tourism". Although the collected information was related to different aspects, such as "studying", "working on deliverables", and "other activities", we have decided to add all these contributions to have a rough idea of the time devoted to OCW activities for each of the considered courses. Figure 6 depicts the mean time students devoted to OCW, for each course, for the 12 weeks covered by the analysis (weeks 4 to $15)$

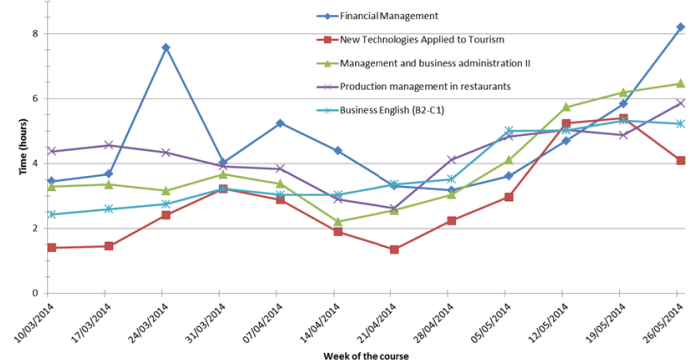

Figure 6. Mean time devoted by students to each course on a weekly basis

In order to ease the comparison among the different courses, it is necessary to take into account the number of ECTS (European Credit Transfer and Accumulation System) credits for each course. Figure 7 shows the mean time students devoted to OCW activities normalised with respect to the ECTS credits for each course.

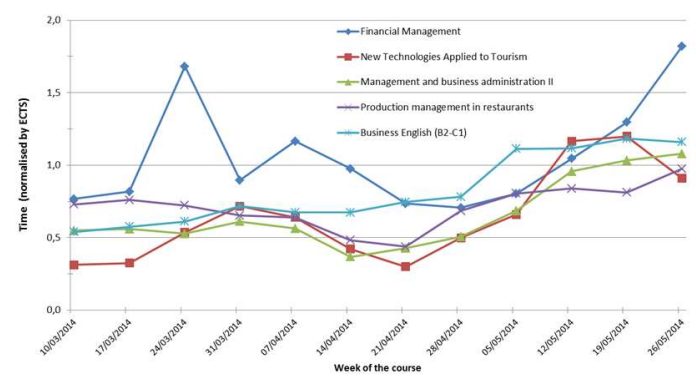

Figure 7. Mean time devoted by students to each course, normalised by ECTS, on a weekly basis

In the UPV, 1 ECTS credit accounts for 10 hours of in-site activities and 15 hours of OCW activities. Taking into account that 1 semester consists of 15 school weeks, it can be concluded that 1 ECTS credit accounts for 1 hour of OCW activity per week. Accordingly, the normalized value 1 in Figure 7 can be interpreted as the OCW students should perform each week. As can be easily seen, the time devoted by students to OCW activities for most of the courses is well below the threshold established. In fact, when considering the mean values for each course, listed in Table 2, it is clear that students' dedication for no course reaches the required 15 hours per week. Either students are not devoting the adequate time to these activities or teachers have not carefully adjusted the time required to complete these tasks. Although data related to the period of study previous to final exams (very significant) and the beginning of 
the course (few significant) is missing, it is clear that assessing the OCW is very important to carefully plan the proposed activities and improve the courses' syllabus.

Table 2. Analysed OCW activities through the associated questionnaires

\begin{tabular}{lccc}
\hline \hline Course & Hours & ECTS & Hours/ECTS \\
\hline \hline $\begin{array}{l}\text { Financial } \\
\text { Management }\end{array}$ & 57,19 & 4,5 & 12,71 \\
\hline $\begin{array}{l}\text { Technologies } \\
\begin{array}{l}\text { Applied to } \\
\text { Tourism }\end{array}\end{array}$ & 34,58 & 4,5 & 7,68 \\
\hline $\begin{array}{l}\text { Management } \\
\text { and business } \\
\text { administration }\end{array}$ & 47,16 & 6,0 & 7,86 \\
\hline $\begin{array}{l}\text { Production } \\
\text { management in } \\
\text { restaurants }\end{array}$ & 51,25 & 6,0 & 8,54 \\
\hline $\begin{array}{l}\text { Business } \\
\text { English }\end{array}$ & 44,50 & 4,5 & 9,89 \\
\hline All courses & 234,6 & 25,5 & 9,20 \\
\hline \hline
\end{tabular}

The analysis of the waveforms depicted in Figure 7 shows a clear trend for all these courses. There is a small peak of OCW activity during the end of March and beginning of April, probably due to midterm examinations. Then, the scarce OCW activity decreases even more at the end of April due to Easter holidays. Finally, OCW activity begins to rise steadily as the end of term approaches. As all the courses follow the very same patterns, it is easy to find in the term periods of very low activity, and periods of heavy workload for the students. It could be interesting to coordinate the requested OCW for all the courses of the same year and term, so students could face a steady demand along that term. This could surely improve students' motivation and dedication, and the quality of the degree as a whole.

\section{Conclusions}

TASCA members have examined the obtained results, first individually (each teacher his/her course) and then in-group (comparing different courses and degrees), and the following conclusions have been drawn:

- Evidently, the greater the amount of information about students, the larger the number of criteria and possibilities teachers would have to improve their teaching. This information enables a better organizing and structuring of courses, and ensures a fair and objective evaluation. "Knowledge is power" is undeniable and if this power is channeled towards a better teaching, the teaching-learning process and students' results will greatly improve.
- Judgmental, opinionated, and/or opportunistic information is a basic feedback to complete students' formative assessment. Usually, teachers only have information about students' results, but if this mutual interchange is brought into $\mathrm{OCW}$, teachers have a complete picture to detect rights and wrongs in the teaching-learning process. Periodically determining the students' degree of satisfaction with the course, in-site and OCW activities is a valuable tool to adjust the course, its syllabus, timetable and activities.

- Collected information can be also used to detect learning problems. When a student provides an excellent deliverable in little time, it may show its efficiency, but when it takes too much time, it could be useful for the student to learn management and organisation to make profitable his/her effort. If the student took way too much time to provide a poor deliverable, then it is necessary to determine what the problem of the student is, but if the poor work was delivered in no time, this is usually the origin of the problem.

After this initial step towards obtaining information about students' OCW to improve activities and courses, TASCA's future work aims at defining a common approach to obtain this information that could be regularly deployed in all our courses. Hence this practice could be seamlessly integrated into the teaching-learning process, favoring a lifecycle for monitoring, analysing, and improving our courses. The deployment of this approach into all the courses of a given year to analyse inactivity and heavy workload periods, and to improve each of these courses individually and the degree as a whole, is also part of TASCA's goals in the near future.

\section{Acknowledgements}

This work has been sponsored by Universitat Politècnica de Valencia's projects PIME 008-A-2013 and PIME/2014/A/022/A

\section{References}

[1] Mohanan, K-P., (2005). Assessing Quality of Teaching in Higher Education. Centre for Development of Teaching and Learning.[Online] http://www.cdtl.nus.edu.sg /publications/assess/default.htm

[2] Bain, K., (2004). What the Best College Teachers Do. Harvard University Press.

[3] Barr, R., and Tagg, G. J., (1995). From teaching to learning - A new Paradigm for Undergrduate Education. Change 27(6), p. 13-15. 
[4] Melmer, R., Burmaster, E., and James S. T. K., (2008). Attributes of Effective Formative Assessment. Washington DC: Council of Chief State School Officers.

[5] Biggs, J., and Tang, C., (2011). Teaching for Quality Learning at University. Open University Press; 4th edition.

[6] Ramsdem, P., (1992). Learning to teach in Higher Education. London: Routledge.

[7] Edgewall Software, (2014). trac - Integrated SCM \& Project Management. [Online] http://trac.edgewall.org/

[8] Redmine, (2014). Redmine project management web application. [Online] http://www.redmine.org/

[9] Universitat Politècnica de València, (2014). PoliformaT.[Online] https://poliformat.upv.es/portal 